\title{
SIMUlaÇÃo DE PLANTA PILOTO PARA A PRODUÇÃo DE BIODIESEL USANDO ÁLCOOL PROVENIENTE DE MANIPUEIRA
}

\author{
MELO J. C. ${ }^{1}$, CAVALCANTI J. V. F. L. ${ }^{2}$, SILVA FÁBIO A. P. ${ }^{2}$, SILVA JOSIVAN P. ${ }^{3}$ e SOUZA \\ THIBÉRIO P. C. ${ }^{2,3}$ \\ ${ }^{1}$ Centro de Tecnologias Estratégicas do Nordeste \\ ${ }^{2}$ Universidade Federal Rural de Pernambuco, Departamento de Engenharia de Alimentos \\ ${ }^{3}$ Universidade Federal de Pernambuco, Departamento de Engenharia Química \\ E-mail para contato: thiberio_souza@ hotmail.com
}

\begin{abstract}
RESUMO - A manipueira é uma água residual da produção de farinha de mandioca com elevada carga poluente e tóxica, que pode degradar cursos d'água e os solos, se não for corretamente descartada. Por outro lado, a produção de farinha é uma importante fonte de renda, sobretudo para pequenos agricultores familiares que, em geral, não têm recursos necessários para tratar esse efluente antes de descartá-lo. Com investimentos da ordem de $\mathrm{R} \$ 800$ mil, a usina da cidade de Lajedo/PE produz etanol para consumo. Este trabalho teve como objetivo simular uma planta piloto para a produção de biodiesel com etanol proveniente da manipueira e óleo de algodão. Foi utilizado o software Aspen para as simulações. Os resultados foram comparados com o biodiesel produzido na usina de Caetés/PE na qual é gerenciada pelo Centro de Tecnologias Estratégicas do Nordeste CETENE. As simulações mostraram uma conversão de $99 \%$ em éster, o que atende ao padrões da ANP (Agência Nacional do Petróleo).
\end{abstract}

\section{INTRODUÇÃO}

A manipueira é uma água residuária da produção de farinha de mandioca com elevada carga poluente e tóxica, que pode degradar cursos d'água e os solos, se não for corretamente descartada (APARECIDO et al., 2013) (FÁBIO et al., 2004). Por outro lado, a produção de farinha é uma importante fonte de renda, sobretudo para pequenos agricultores familiares que, em geral, não têm recursos necessários para tratar esse efluente antes de descartá-lo (MACHADO et al., 2009). O estado de Pernambuco possui uma usina piloto desinada a produção de etanol oriundo do efluente hídrico das casas de farinha. A usina, que recebeu investimento de $\mathrm{R} \$ 800 \mathrm{mil}$, é o primeiro projeto do Programa Vera (Valorização Energética de Resíduos da Agropecuária e Agroindústria), que tem como objetivo o desenvolvimento tecnológico e a implantação de unidades de aproveitamento de resíduos para produção de energia renovável, especialmente em economias familiares. O principal objetivo da usina é a produção de bioetanol que é destinado a instituições de pesquisa no estado e, após certificação da Agência Nacional de Petróleo e Biocombustíveis (ANP), será utilizado para abastecer os veículos da prefeitura de Lajedo e do governo do estado. A usina produz também biogás, o qual é utilizado para suprir suas próprias necessidades energéticas, e biofertilizante que é empregado na agroindústria da mandioca e no campo experimental da unidade. A usina experimental é um sistema integrado formado 
por biodigestores, uma central de utilidades (cogeração) e uma microdestilaria de álcool de manipueira. A usina cria um sistema de alimentação recíproca no qual os rejeitos da microdestilaria (vinhaça) e a matéria prima excedente (manipueira) constituirão a massa biodegradável para os digestores, enquanto que o biogás produzido alimentará a central de utilidades que fornecerá energia térmica e elétrica para a microdestilaria. A usina experimental de Lajedo produz anualmente 70.000 litros de bioetanol. Atualmente, a unidade tem capacidade instalada para processar 4,8 milhões de litros de manipueira por ano, o que corresponde a $20 \%$ da produção de farinha do município. Outra vertende deste trabalho está na segunda etapa do processo. A usina de biodiesel localizada na cidade de Caetés/PE. Com a produção de biodiesel fazendo uso da rota etílica a partir do álcool proveniente da usina de Lajedo, o ciclo energático é fechado de forma ecologicamente correta. Este trabalho visou estudar do ponto de vista computacional, um processo produtivo de duas plantas piloto (etanol e biodiesel) integradas utilizando o APEN/HYSYS. Os resultados das simulações foram comparados com os resultados obtidos no processo.

\section{MATERIAIS E MÉTODOS}

O efluente usado no processo é oriundo das casas de farinha da região de Lajedo/PE. A mandioca é processada pelos agricultores que descartam o resíduo no qual é levado para a usina de piloto instalada na cidade. O efluente passa por um processo de hidrólise onde o amido contido no efluente é convertido em açucares redutores. O processo consiste em uma etapa ácida e uma etapa enzimática para a conversão do amido. Na hidrólise enzimática é utilizado um complexo de enzimas alfa-amilase que fazem a maior parte da transformação. Em seguida, o produto é direcionado para a etapa fermentativa, onde é inserido o fermento (levedura) a fim de se converter os açúcares em álcool. Por fim, o líquido fermentado é enviado para a etapa de destilação onde é separado o etanol. A Figura 1 mostra o processo fermentativo e o processo de destilação. As informações do processo são usadas como dados para a simulação no Aspen® com o objetivo de se otimizar ao máximo a produção de etanol reduzindo assim o gasto de processo secundário (usina de Caetés/PE).

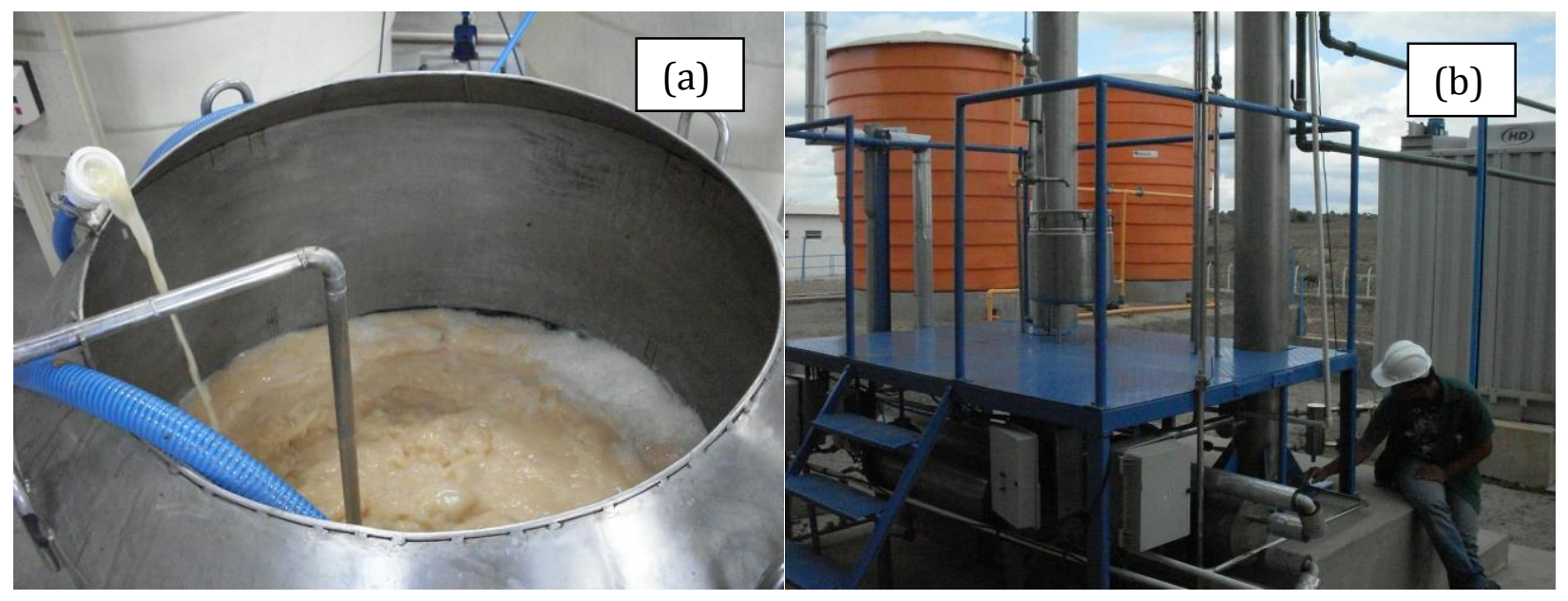

Figura 1: Processo fermentativo (a), colunas de destilação da usina de Lajedo/PE (b). 
Com teor alcoólico em torno de $85 \%$ em volume, o álcool da usina de Lajedo é direcionado para a usina de Caetés/PE para a produção de biodiesel. A Figura 2 mostra o fluxograma do processo etílico simulado no Aspen ${ }^{\circledR}$.

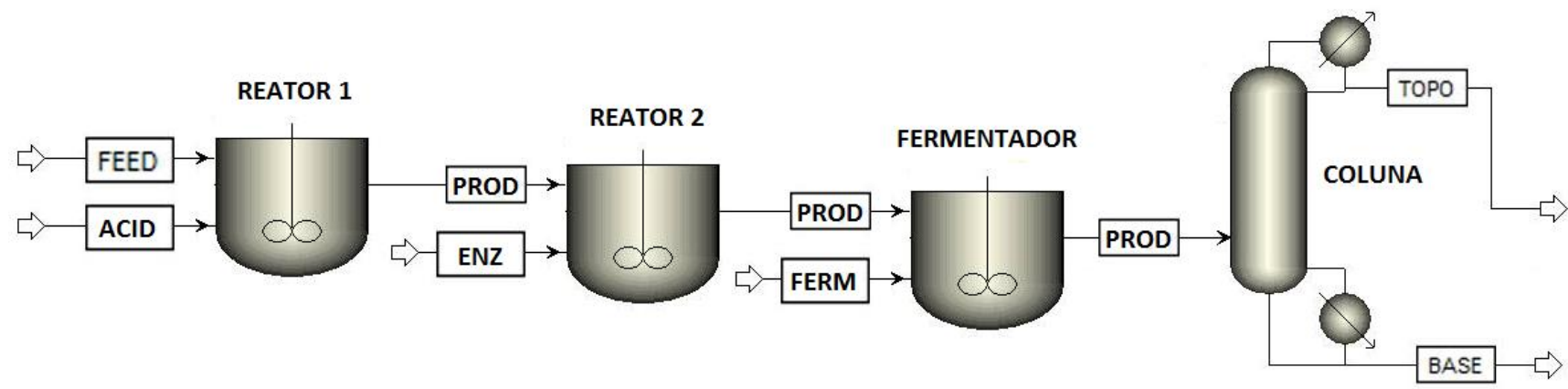

Figura 2: Fluxograma do processo produtivo de etanol da usina de Lajedo/PE.

Em seguida, foi utilizado os dados do processo das instalações industrias da usina de biodiesel de Caetés/PE (Figura 3) para a produção do biocombustível a partir do etanol gerado em Lajedo/PE. As informações coletadas no processo serviram de dados para as simulações no Aspen®.
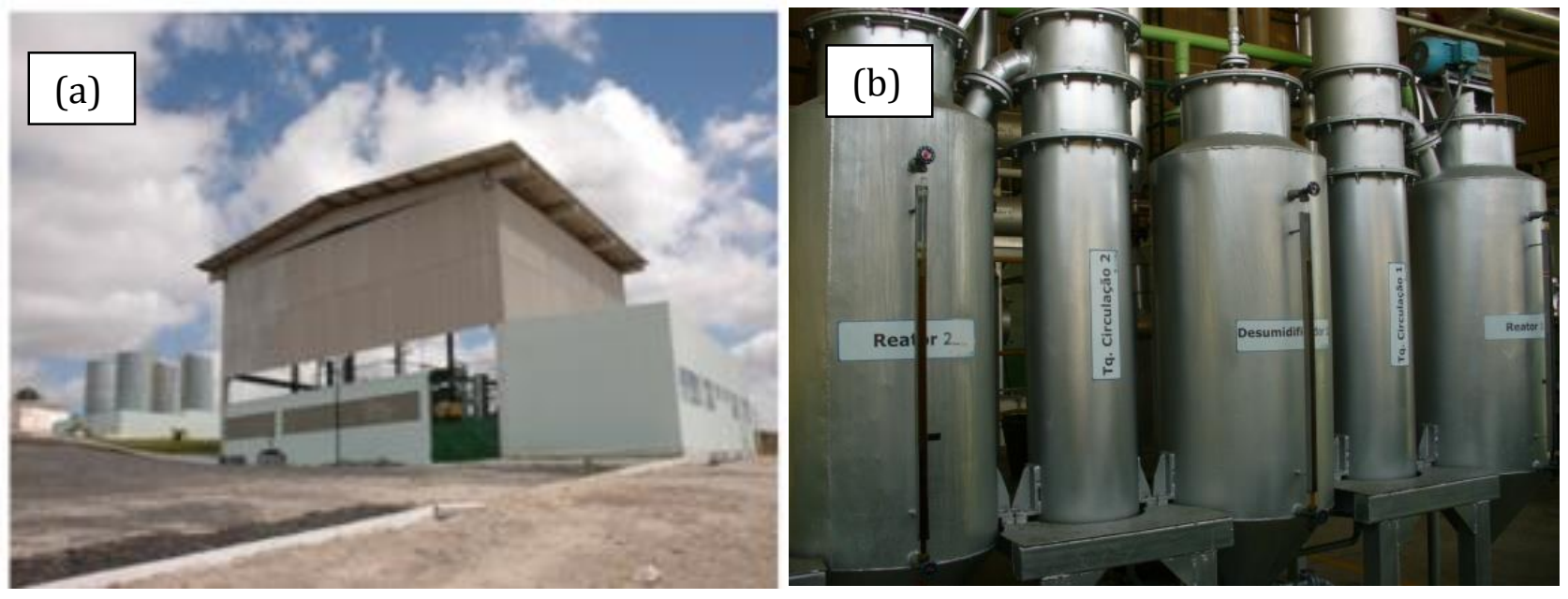

Figura 3: Usina de Biodiesel de Caetés/PE. Reatores de biodiesel (b).

Inicialmente o etanol hidratado oriundo da usina de Lajedo/PE é tratado por destilação extrativa antes de ser direcionado para a etapa de produção de biodiesel a fim de se remover a água contida evitando problemas de reações paralelas como a saponificação. A coluna de extração opera de forma a aproveitar a própria glicerina gerada na usina como solvente. A glicerina possui uma afinidade pela água, extraindo-a por arraste através da coluna. $\mathrm{O}$ etanol, mais leve no processo, é retirado no topo da coluna. Em seguida, o etanol é direcionado para os reatores onde recebe o óleo de algodão e o catalisador $(\mathrm{NaOH})$ para dar início da reação de transesterificação. Após um ciclo de uma batelada (1 
hora), o produto reacional é direcionado para um sistema de decantação onde são separados o éster (biodiesel) e a glicerina. A Figura 4 mostra o fluxograma do processo simulado no Aspen®.

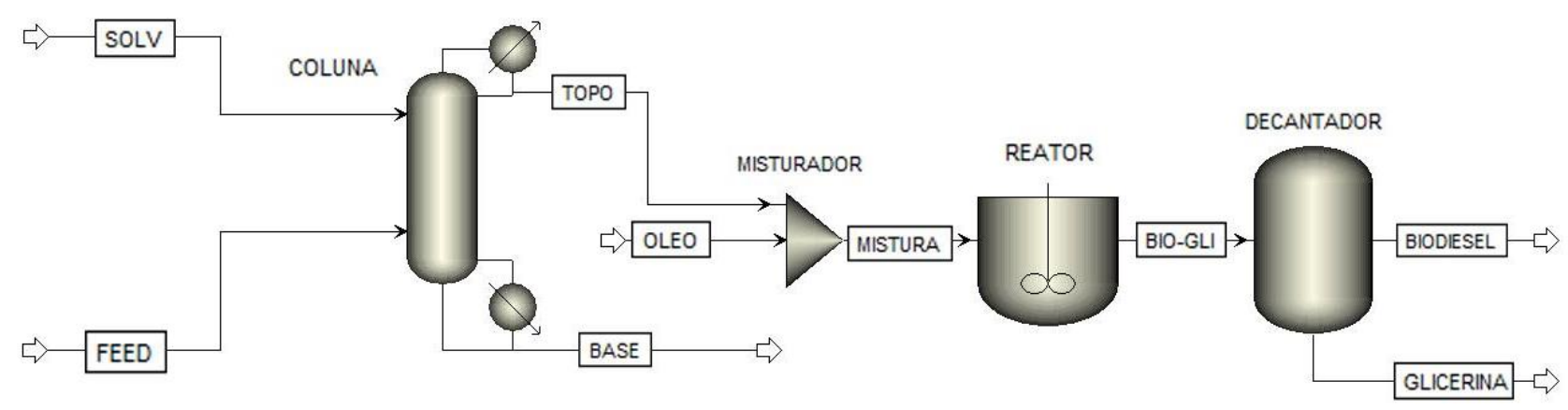

Figura 4: Fluxograma do processo para produção de biodiesel a partir do etanol de manipueira.

Os resultados das simulações foram comparados com os resultados obtidos nos processos.

\section{RESULTADOS E DISCUSSÃO}

O software de uso comercial Aspen Plus ${ }^{\circledR}$ User Interface ${ }^{\circledR}$ da Aspen Tech ${ }^{\circledR}$ é uma ferramenta de modelagem de processo apropriada para o projeto conceitual, otimização e monitoramento do desempenho para a indústria química. Neste trabalho este simulador foi de fundamental importância, pois com o desenvolvimento do fluxograma da Figura 4 foi possível obter diversas informações importantes sobre a produção de biodiesel utilizando álcool da manipueira.

O trabalho partiu do álcool obtido na usina de Lajeto/PE. O teor de etanol conseguido experimentalmente na usina foi de $85,6 \%$. A simulação do processo mostrou um resultado de $86,3 \%$ para o mesmo de álcool. O álcool obtido na usina foi enviado para a usina de Caetés/PE a fim de se purifica-lo através de destilação extrativa a ponto de ser usado na produção de biodiesel.

A coluna de destilação/extração é responsável pela purificação do álcool produzido pela fermentação do efluente da manipueira. A coluna simulada tem 31 estágios de equilíbrio, onde a glicerina (solvente) foi alimentada no $2^{\circ}$ estágio da coluna (Top/Down), contando de cima para baixo na coluna, e a manipueira fermentada foi alimentada no $19^{\circ}$ estagio.

Os resultados do perfil de concentração na coluna obtido pela simulação podem ser vistos na Figura 5. Nesta figura é possível observar como a concentração de cada componente da mistura varia ao longo da coluna. No estágio 1 (condensador do tipo total) é possível observar que a concentração de etanol é alta chegando a 98,3\% mássico (vide Tabela 1). A extração de etanol na coluna chegou a ser de 13,3\% uma vez que o álcool de manipueira possuía um teor de $85 \%$. Ao longo da coluna, pode-se observar o aumento da concentração de glicerina e da água, quando estes se aproximam da corrente de 
fundo. Isto se dá devido ao arraste da água pela glicerina. No estágio 19, existe uma variação no fluxo interno da coluna em função da corrente de alimentação da manipueira. No fundo da coluna, pode-se observar a queda brusca na concentração de álcool no refervedor (tipo parcial) devido ao aumento de temperatura o composto mais volátil (etanol).

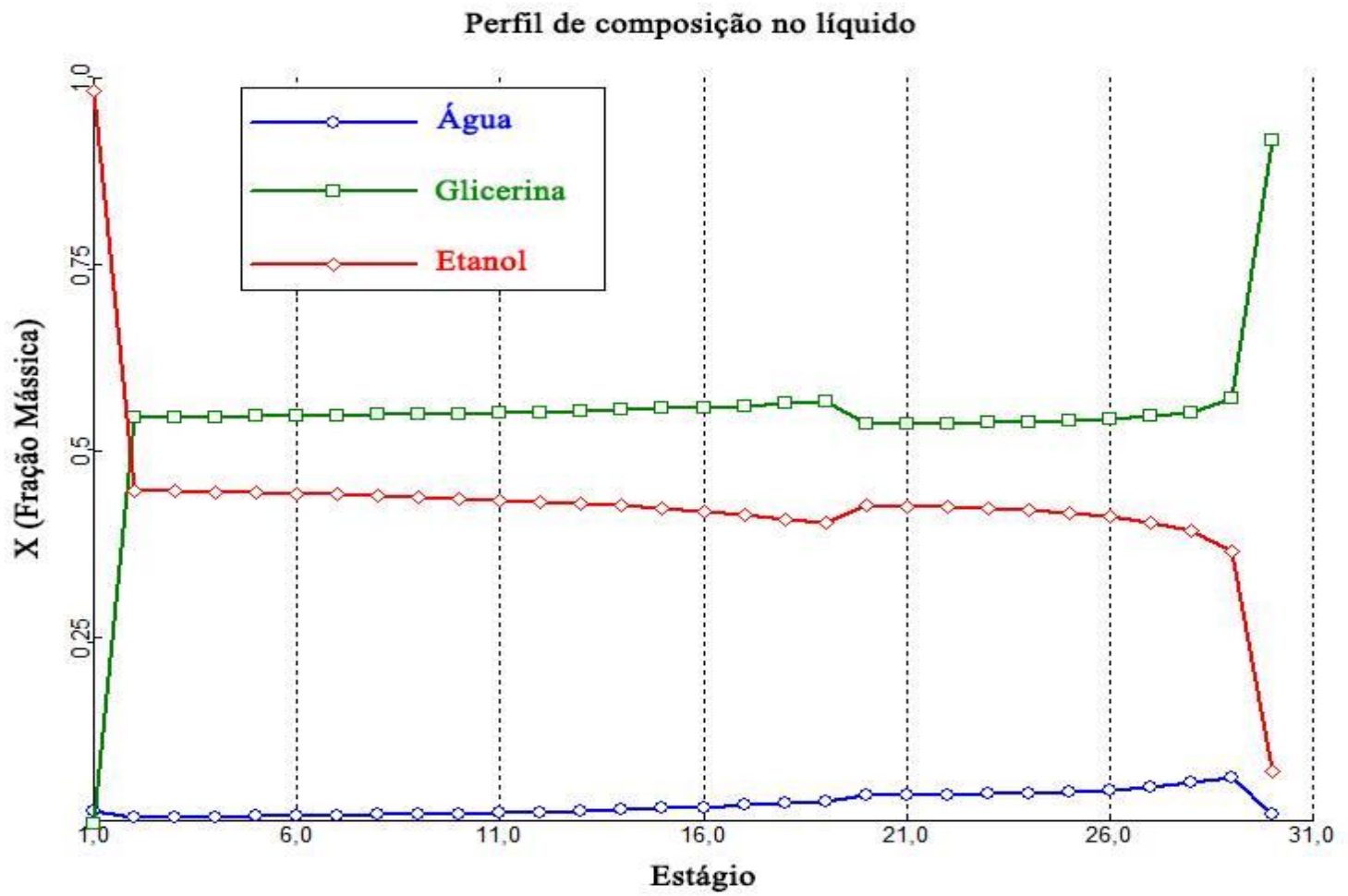

Figura 5: Perfil de concentração dos componentes ao longo da coluna de destilação/extração.

A Tabela 1 mostra as informações referentes as correntes de entrada e saída do processo de destilação extrativa. Como vazão de trabalho, foi escolhido um fluxo de glicerina e de álcool de manipueira na coluna de $1.000 \mathrm{Kg} / \mathrm{h}$ e $100 \mathrm{Kg} / \mathrm{h}$ respectivamente. A temperatura na base da coluna foi de $119,096^{\circ} \mathrm{C}$ e a temperatura no condensador de $78,199^{\circ} \mathrm{C}$ para se obter um melhor nível de operação. Além destas condições foi necessária uma razão de reciclo alta para melhorar a pureza do etanol.

Com o resultado foi possível eliminar 99,8\% dá água da manipueira pela corrente de fundo da coluna de extração, levando a uma fração mássica de $99,8 \%$ em etanol na corrente de topo, proveniente do condensador.

Partindo desta matéria prima (efluente de manipueira) a usina experimental de Caetés, no interior do estado de Pernambuco, consegue obter um biodiesel com 98\% em éster, utilizando 3 reatores paralelos que operam em regime de batelada. O tempo de residência trabalhado foi de 1 hora e 30 minutos a uma temperatura de $60^{\circ} \mathrm{C}$. 
Tabela1: Condições das correntes materiais do processo.

\begin{tabular}{r|rrrr} 
& Base (referv.) & Manipueira & Glicerina & Topo (cond.) \\
\hline Temperature $\left.{ }^{\circ} \mathrm{C}\right)$ & 119,096763 & 70 & 90 & 78,1992679 \\
Pressão $(\mathrm{bar})$ & 1,01325 & 1,01325 & 1,01325 & 1,01325 \\
Fluxo mássico $(\mathrm{kg} / \mathrm{hr})$ & 1092,00001 & 100 & 1000 & 7,99999948 \\
Fluxo volumétrico $(\mathrm{cum} / \mathrm{hr})$ & 0,94775368 & 0,12975761 & 0,81953018 & 0,01086045 \\
Enthalpy Gcal/hr & $-1,8400208$ & $-0,1757231$ & $-1,6972852$ & $-0,0115283$ \\
Fluxo mássico $(\mathrm{kg} / \mathrm{hr})$ & & & & \\
Água & 14,8647511 & 15 & 0 & 0,13524897 \\
Glicerol & 999,999298 & 0 & 1000 & 0,00071197 \\
Etanol & 77,1359565 & 85 & 0 & 7,86403854 \\
Fração Mássica & & & & \\
Água & 0,0136124 & 0,15 & 0 & 0,01690612 \\
Glicerol & 0,91575027 & 0 & 1 & $8,90 \mathrm{E}-05$ \\
Etanol & 0,07063732 & 0,85 & 0 & 0,98300488 \\
Aluxo volumétrico líquida (cum/hr) & 0,01489339 & 0,0150289 & 0 & 0,0001355 \\
Glicerol & 0,7948626 & 0 & 0,79486316 & $5,66 \mathrm{E}-07$ \\
Etanol & 0,09740178 & 0,10733194 & 0 & 0,00993014 \\
Água & 0,01641765 & 0,12282449 & 0 & 0,01346181 \\
Glicerol & 0,87621207 & 0 & 1 & $5,62 \mathrm{E}-05$ \\
Etanol & 0,10737028 & 0,87717551 & 0 & 0,98648197
\end{tabular}

Por fim, foi possível comparar os resultados da simulação com os resultados obtidos na usina. Os resultados simulado e o experimental podem ser vistos na Tabela 2.

Tabela 2: Valores obtidos para os resultados reais e simulados.

\begin{tabular}{r|cccc} 
& $\begin{array}{c}\text { Usina de Lajedo } \\
\text { (real) }\end{array}$ & $\begin{array}{c}\text { Usina de Lajedo } \\
\text { (simulado) }\end{array}$ & $\begin{array}{c}\text { Usina de Caetés } \\
\text { (real) }\end{array}$ & $\begin{array}{c}\text { Usina de Caetés } \\
\text { (simulado) }\end{array}$ \\
\hline Etanol (Volume) & $85,6 \%$ & $86,3 \%$ & $97,3 \%$ & $98,3 \%$ \\
Biodiesel (Conversão) & --- & --- & $98,6 \%$ & $99,1 \%$
\end{tabular}

É possível observar que os resultados da simulação representam bem o processo industrial uma vez que estão muito próximos dos resultados experimentais obtidos na indústria validando assim o trabalho de simulação. 


\section{CONCUSÃO}

O presente trabalho propõe alternativas de uso de rejeitos industriais como o efluente da manipueira e a glicerina proveniente do biodiesel. Estas substâncias, que seriam prejudiciais ao meio ambiente, podem ser reutilizadas no processo de produção de biodiesel, levando a produtos de maior valor agregado. As simulações obtidas por este trabalho mostram que o efluente da manipueira pode ser utilizado para a produção de etanol, partindo de um processo de hidrólise e posteriormente uma fermentação, obtendo-se como produto um álcool com $85 \%$ em massa de etanol. O álcool produzido pela usina sofrer um processo de destilação-extrativa junto com a glicerina, que também é um coproduto na produção do biodiesel. Com este processo é possível produzir etanol com 98,3\% de pureza em massa permitindo a sua utilização no processo de produção de biodiesel. Com o etanol produzido, é possível obter um biodiesel com teor de éster de $98 \%$, o que atende as especificações estipuladas pela ANP (Agência Nacional de Petróleo e Biocombustíveis). De forma geral é possível concluir que a simulação representa bem o processo real, e que o efluente da manipueira pode ser utilizado na produção de etanol e posteriormente na produção de biodiesel, gerando um combustível mais verde e renovável.

\section{REFERÊNCIAS}

APARECIDO ALMEIDA CONCEIÇÃO, ANGRA PAULA BONFIM RÊGO, HUGO SANTANA, INGRID TEIXEIRA, AMANDA GILVANI CORDEIRO MATIAS, Tratamento de efluentes resultantes do processamento da mandioca e seus principais usos, Revista Meio Ambiente e Sustentabilidade | vol.4 n.2 | jul/dez 2013.

FÁBIO MARQUES APRILE, ANTÔNIO HELDER PARENTE, MARC BOUVY, Análise dos resíduos industriais do processamento da farinha de mandioca na bacia do rio tapacurá (pernambuco - brasil), bioikos, puc-campinas, 18 (1): 63-69, 2004.

MACHADO, ANA MERCEDES CORRÊA, PEDROTTI, ALCEU.PERSPECTIVA, Energética para Pequenas Unidades Fabris: Casas de Farinha do Município de Campo do Brito - Sergipe, Resumos do VI CBA e II CLAA, Rev. Bras. De Agroecologia/nov. 2009 Vol. 4 No. 2 